\section{FIORDS AND OTHER INLETS OF THE} $S E A .^{1}$

I IKE an experienced teacher, Prof. Gregory L begins his book on "The Nature and Origin of Fiords" by a definition of its subject. Fiord is a Scandinavian word, and fiords are common on a large part of the coast of Norway, but the term is often used vaguely, and sometimes, as we shall see, with unjustifiable restrictions. With him it denotes an inlet of the sea, bounded by lofty and steep opposing walls; piercing far into the land, and consisting of long straight reaches, which turn and receive their tributaries at sharp angles. Thus, though a fiord is a sea-drowned valley, not all such valleys can be called fiords. It has been carved, as the definition suggests, in a plateau more or less elevated, which consists of hard rocks, and it is named a fiard when this plateau is low, the difference between the two being obviously varietal rather than specific, and a comparatively slight elevation, on such a coast as that of Norway, might show the one to end in the other. It remains narrow to its seaward end, thus differing from an ordinary estuary, which widens in that direction, so that waves may have helped in forming it, while they have done little for the fiord; and when one of the former has an irregular outline, and is bordered by bold rugged hills, it is designated a ria, from a Spanish name. Fiords are frequent in the northern and southern portions of the globe, and practically absent from the more tropical regions; they also often bear marked signs of glaciation. That, however, does not prove them to have been excavated by ice, or justify refusing to give the name fiord to a submerged valley with the other qualifications, for any such limitation is importing a hypothesis into a definition. This geographical distribution, however, is a fact, and Prof. Gregory attributes it to terrestrial conditions, which make oscillations in level more frequent in the higher than in the lower latitudes.

From this preliminary discussion he proceeds to describe concisely the fiords in the several parts of the globe, in order to ascertain, by inductive study of their phenomena, by what agencies they may have been formed. Beginning with those of Norway, the home of the name, he points out the more important features in each, its relation to the neighbouring district, its outline and dimensions, with details, whenever obtainable, of its subaqueous contour. The Sogne fiord in Norway, one of the most accessible to English visitors, exhibits the characteristic features of such an inlet, especially in its upper branches, not less distinctively than that grand example, Milford Sound, in New Zealand (Fig. $x$ ). The sides, to summarise Prof. Gregory's description, are high and steep,

1 "The Nature and Origin of Fiords." By Prof. J. W. Gregory, F.R.S. Pp. $x v i+54^{2}+$ viii plates. (London: John Murray, 1913.) Price $16 s$. net. NO. 23 I I, VOL. 92] not broken by deep gullies, so that the streams rising on the uplands frequently descend as waterfalls over the walls instead of as cataracts hidden in deep gullies. We may therefore conclude that these cascades are comparatively modern-more modern, for instance, than in the Alps, where the other habit is the more common. Those sidewalls also are often subparallel, so that the fiords for considerable distances are uniform in width, their valleys also taking a straight course. The most typical Norway fiords are surprisingly deep, the maximum in the Sogne fiord being almost $4000 \mathrm{ft}$., and the walls descend for a long way beneath the surface of the water with as steep a slope as they have for some $2000 \mathrm{ft}$. above it. Thus a cross-section of their floors is trough-like, but the longitudinal one is a concave curve. In

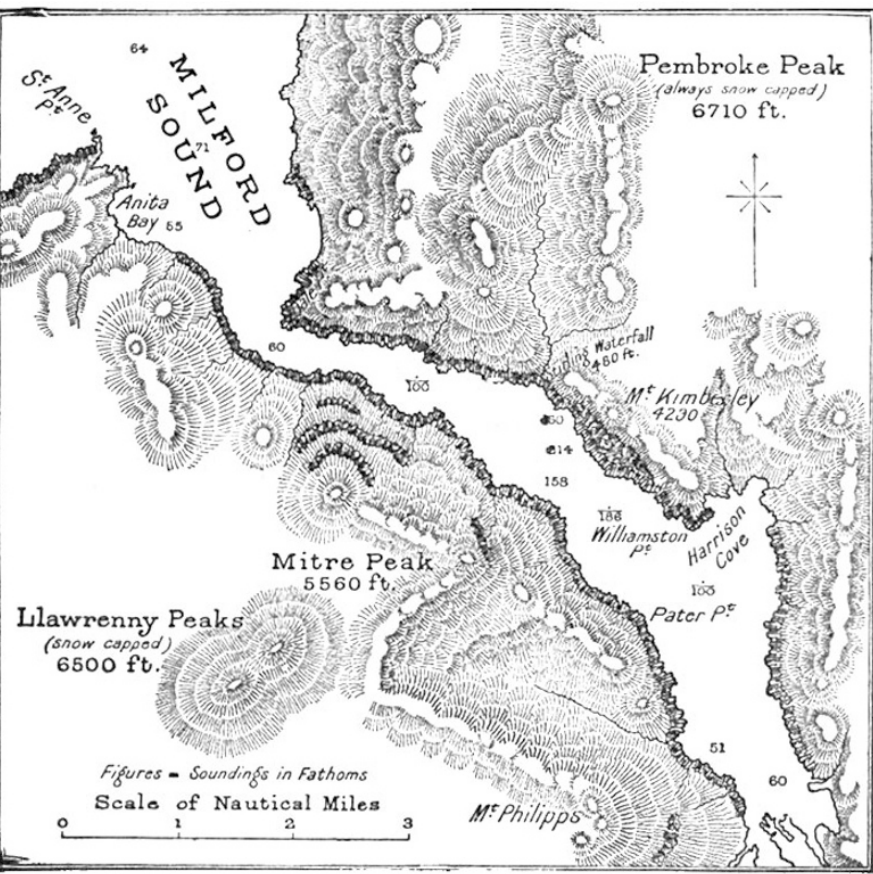
Ziords."

some cases the fiord bed rises and falls more than once in this direction, as in some Alpine and Scotch lakes, but in most cases, though not in all, the fiord has an outer (submerged) rim, sometimes narrow, sometimes comparatively wide, which prevents a free influx of the deeper ocean water. This, though it may sometimes consist of moraine deposited by a retreating glacier, or of ordinary detritus, like the bar at the mouth of an estuary, must often be, as Prof. Gregory explains, a true rock barrier. This last characteristic, together with their ice-worn rocks, the truncation of spurs from the mountain on either side, and their geographical distribution, have caused some geologists not only to attribute fiords to glacier erosion, but also to refuse the name to any similar submerged valley which could not have been formed in this way. 
But besides the general objection to this limitation, which has already been mentioned, the Dalmatian coast can show fiords as characteristic as those of Norway, though glaciers can never have been more than unimportant features on even the highest of the Dinaric Alps (Fig. 2). A glacier which continues to descend a main valley after those in the lateral glens have shrunk and ceased to be tributaries, may have converted the latter into hanging valleys; its ice-stream may have replaced the rugged ends of spurs by smooth facets, but a river also, in similar circumstances, can produce the one and the other, and, in many cases, as Prof. Gregory shows, it can be proved that the valleys occupied by fiords are pre-glacial.

But, as he proceeds to point out, the larger in the Geological Magazine for 1905, where the surface is comparatively "raw"; for the "leading lines " in such an example as the Jordan valley can only be discovered by close study of the geology. In such cases the older name, trough-fault valley, seems preferable. Apart, however, from this question of nomenclature, Prof. Gregory supports his view, both against ice-excavation and in favour of earth movements, as the primary cause of fiords, with arguments which will be very difficult to overthrow. But we must conclude, and do this by expressing our hearty thanks to him for this admirable history of fiords and other forms of inlets of the sea. It will be a great boon to students, for it is a veritable encyclopædia, full of important facts, the collection of which must have entailed long and patient labour, because they are scattered

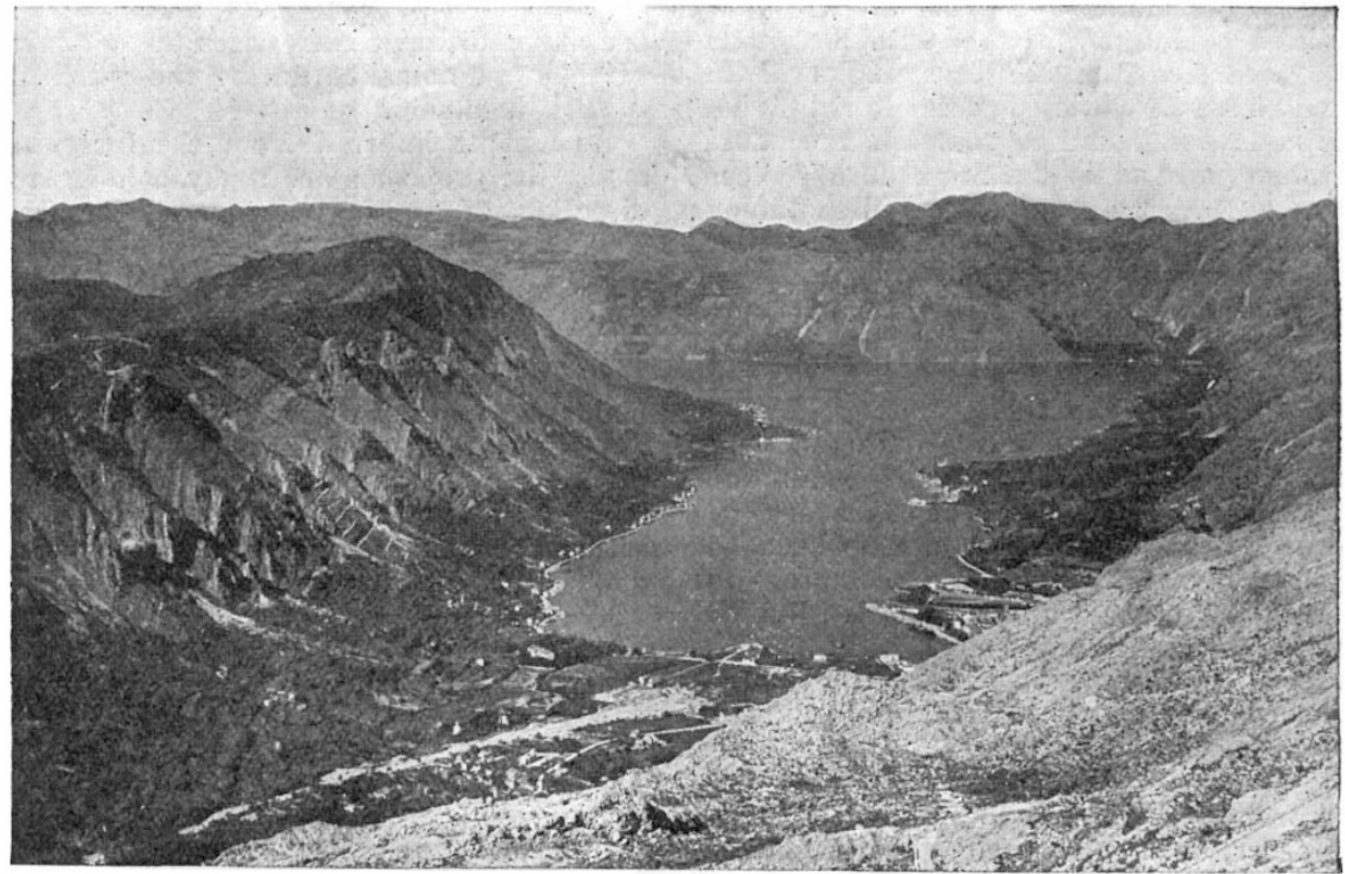

Fig. 2.-Cattaro Bay, the inner Bratsch of the Cattaro Fiord. The spurs on the fault.block on the left side of the view show triangular facets due to faulting. The precipitous slope above Cattaro, on the right margin of the view, is a fault-scatp. From "Ihe

features of fiords--the straight channels terminated by a sharp twist, the high angles made by tributary valleys, indicate a close connection with the greater earth movements which have determined the main physical features of the region. A set of diagrams brings out clearly the frequent relation between the fiords, the lakes, the mountain ranges, and the shore lines in different regions, showing that the first and second very frequently follow the course of important faults. This seems indubitable, but we must remember that the work of the latter, though indispensable as a preliminary, has had an indirect, rather than a direct, effect in producing the present scenery. In regard to this a too frequent use of the term "rift valleys" may sometimes mislead: for a rift means a lateral rather than a vertical displacement, and should only be applied, as I pointed out about many publications in sundry languages, and often not readily accessible.

\section{T. G. BONNEY.}

\section{EDLCATIONAL LEGISLATION IN NEW SOUTH WALES.}

THE economic, social, and educational problems which present themselves for solution in the free atmosphere of our more prosperous colonies, unhampered by tradition and conventions, and with their fresher outlook, often present features in the attempt to solve them well worthy the attention and possibly the emulation of those engaged upon similar questions at home.

We are on the eve of great educational changes, if we are to trust the somewhat vague utterances of the Lord Chancellor and of the Minister for

NO. 23 I , VOL. 92] 